Raf. J. Sci.,Vol.28, No.2 Special Issue for the Third Scientific Conference of Chemistry, pp.164-174, 2019

\title{
Storage Stabilityand Compatibility of Dura Asphalt Modified by SBS
}

\author{
Doha N. Saad* \\ Eman I. Ahmed \\ Department of Chemistry/ College of Science/ University of Mosul
}

*E-mail: dddddhhhh335@gmail.com*

(Received 18/9/2018; Accepted 25/10/2018)

\begin{abstract}
The purpose of this study was to characterize the physical behaviour of Dura asphalt modified by styrene-butadiene-styrene (SBS)co-polymer. The polymer modified asphalt (PMA) was produced by mixing a 40/60 penetration grade Dura (base) asphalt withdifferent ratios of the copolymers. The resultsthus exhibited that the modification of the authentic asphalt by SBS had great impact on the physical properties of the asphalt. Furthermore, the high temperature performance of the original asphalt was enhancedsuch that the morphology observed by microscope examinationrevealed the compatibility between SBS and asphalt. Additionally, the storage stability of the binder was significantly improved in comparison with Dura asphalt.
\end{abstract}

Keywords: Asphalt, SBS, compatibility, Storage stability.

\section{أسقرارية الخزن والتوايقية لأسفلت الوره المجهر بولمطة SBS}

\author{
المالid

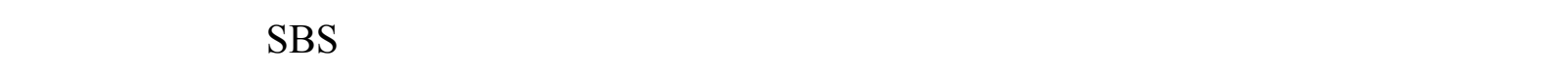 \\ لختراقية 40/60 حيث لن كمية ل SBS له تأ ثير كبير على الخصائص الريولوجية للإبفلت والتعسن في أدائه العالي تجهل \\ الحرارة اله حد كبير، كما مم درلسة توافق الأسفلت مع SBS وذلك بدرلسته من خلال المايكروسكوب ولسٔققرارية الخزنإذ

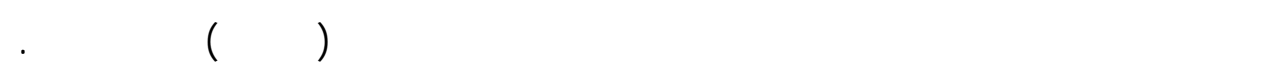 \\ الهاملت الدالة: لسٔفلت، SBS، توافقية، لسقرارية الخزن.
}

\section{INTRODUCTION}

Asphalt is a highly complex hydrocarbon compound with high molecular weight,and high degree of hardness, and plasticity at prevailing temperatures (Salih, 2008).

The modification of asphalt had been shown to improve the performance ofthe pavement. Pavements constructed with modified binders have some merits,such as resistance rutting and thermal cracking, as well as decreasing fatigue damage, stripping and temperature susceptibility. Modified binders have been used with success at locations of high stress, such as at intersections of busy streets, airports and vehicle weigh stations (Kareem, 2016). Styrene-Butadiene-Styrene (SBS) is one of the elastomeric polymer that was widely used to improve properties of asphalt binder.SBS polymer exhibits a two-phase morphology consisting of glassy polystyrene (PS) end blocks connected together by the rubber polybutadiene (PB) segments. The hard PS end blocks provide SBS its high tensile strength and flow resistance at high temperature. The rubbery PB mid blocks provide elasticity, fatigue resistance, and flexibility at low temperatures. When SBS is mixed with hot asphalt, the PS end blocks begin to soften while PB mid blocks start absorbing the maltene component present in asphalt and begin to swell. Cooling of this blend leads to the formationof 
strong, elastic and three-dimensional network of polymers within asphalt (Swamy et al., 2017). Many researchers have shown their interest in studying the properties of the modified binders and evaluating their advantage over the conventional asphalt. The major studies carried out by different researchers using Styrene Butadiene Styrene (SBS), Airey (2003) found of the effect of SBS polymer modification on the conventionalpolymer content. Although the decrease in penetration is relatively in uniform with increasing polymer content but there isa significant larger increase in softening point at high polymer content of 5\% and 7\%. In addition to the increase in stiffness, the increased penetration indices of PMB indicate a significant reduction in temperature susceptibility with polymer modification particularly at higher polymer content (Airey, 2003; Zhang et al., 2010) studied the effect of ageing on rheological properties of storage-stable SBS/sulfur-modified asphalts. Asphalt compounds can be separated by chromatographic techniques into four generic groups (SARAs): saturates, aromatics, resins (which make up the maltene fraction) and asphaltenes. The complexity, aromaticity, heteroatom content, and molecular weight increase in the order [ $\mathrm{S}<\mathrm{A}<\mathrm{R}<\mathrm{As}$ ], as shown in Fig. (1) (Navarro and Partal, 2009). There are obvious differences in physicochemical properties among SARA fractions, which havesignificant effects on properties of asphalt binder (Firoozifar and Foroutan, 2014). The term "compatibility" was introduced to describe the "level ofinteractions" between the asphalt and polymer. This term has an intuitive significance but remainsan evanescent property that is rather difficult to be directly measured. Several methods weretherefore developed over the years to indirectly estimate compatibility in asphalt/polymer blends.From this perspective, the investigation of the blend morphology is probably the most direct methodand optical microscopy is the most popular method because it allows the rapid and economicalobservation of the sample. A picture obtained using optical microscopy allows for a meaningfulrepresentation of compatibility and can be successfully used to predict the macroscopic stability ofthe blend. (Polacco et al., 2015).

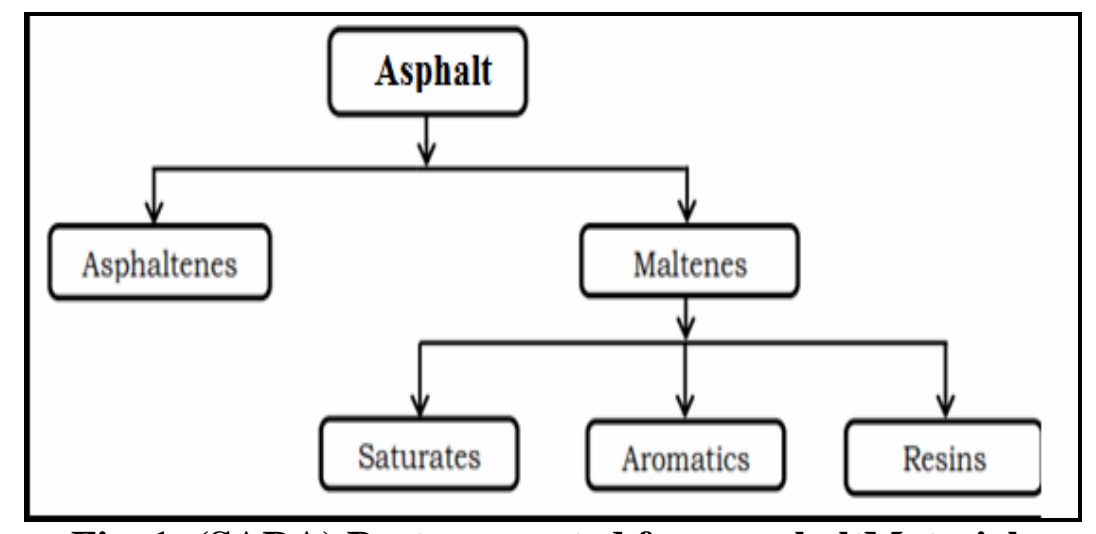

Fig. 1: (SARA) Parts separated from asphaltMaterials

\section{EXPERIMENTAL}

The materials used in this study are:

\section{Asphalt:}

One type of asphalt binder wasused in this study.It is (40-50) penetration grade from DuraRefinery. The physical properties of asphalt before added SBS that are used aretabulated in (Table 1). 
Table 1:Physical properties of asphalt before add SBS

\begin{tabular}{|c|c|}
\hline General physical properties & The value in modified \\
\hline Specific Gravity @ $15.6^{\circ} \mathrm{C}$ & 1.04 \\
\hline Flash point ${ }^{\circ} \mathrm{C}$ & 326 \\
\hline Ductility @ $25^{\circ} \mathrm{C}(\mathrm{cm})$ & $100+$ \\
\hline \% wt. Solubility. in $\mathrm{CH}_{2} \mathrm{CL}_{3}$ & 99.9 \\
\hline Penetration. @ $25^{\circ} \mathrm{C}(100 \mathrm{gm}, 5 \mathrm{sec} .0 .1 \mathrm{~mm})$ & 40 \\
\hline Original of penetration After loss on heat \% & 92 \\
\hline Softening point ${ }^{\circ} \mathrm{C}$ & 51.5 \\
\hline $\mathrm{H}_{2} \mathrm{O} \% \mathrm{Vol}$ & NIL \\
\hline
\end{tabular}

\section{2- Additives:}

Styrene-Butadiene-Styrene polymer (SBS) D1192in the form of porous pellet was obtained from Kratonpolymers (USA). As shown in Fig. (2).
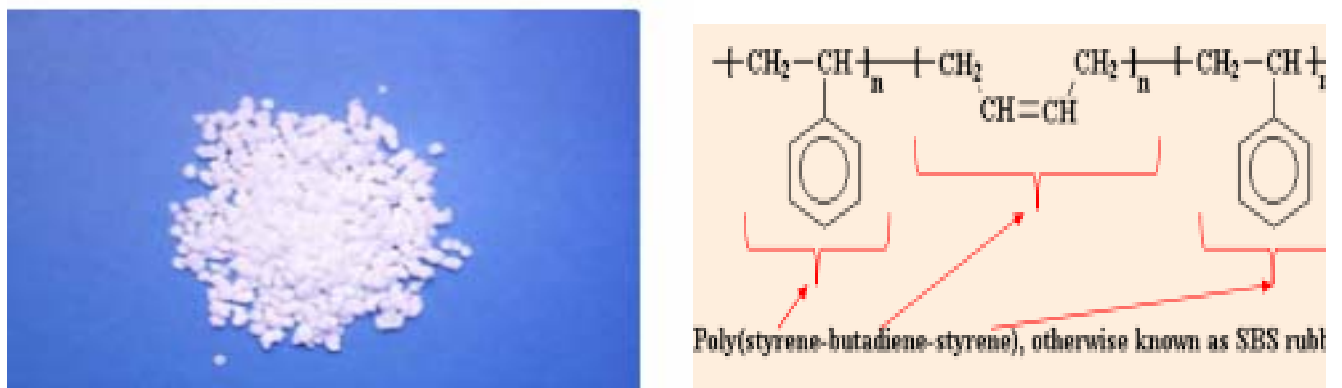

Fig. 2: A; Image of material SBS , B; Chemical formula SBS

\section{Preparation of Sample}

To prepare the blends of the modified binders, $(100 \mathrm{gm})$ of asphalt binder was placed in the 1litr metal container and heated to fluid state. The mixing of modifiers is carried out using a mechanical stirrer. Asphalt binder was heated to a temperature of $160^{\circ} \mathrm{C}$ and the appropriate quantity of SBS copolymer was added separately inmetal container at given Fig. (3). The SBS modified binder, mixture was maintained attemperature between $\left(160-165^{\circ} \mathrm{C}\right)(\mathrm{Al}$-Layla, 2006) and contents were gradually stirred for about 5 hours.

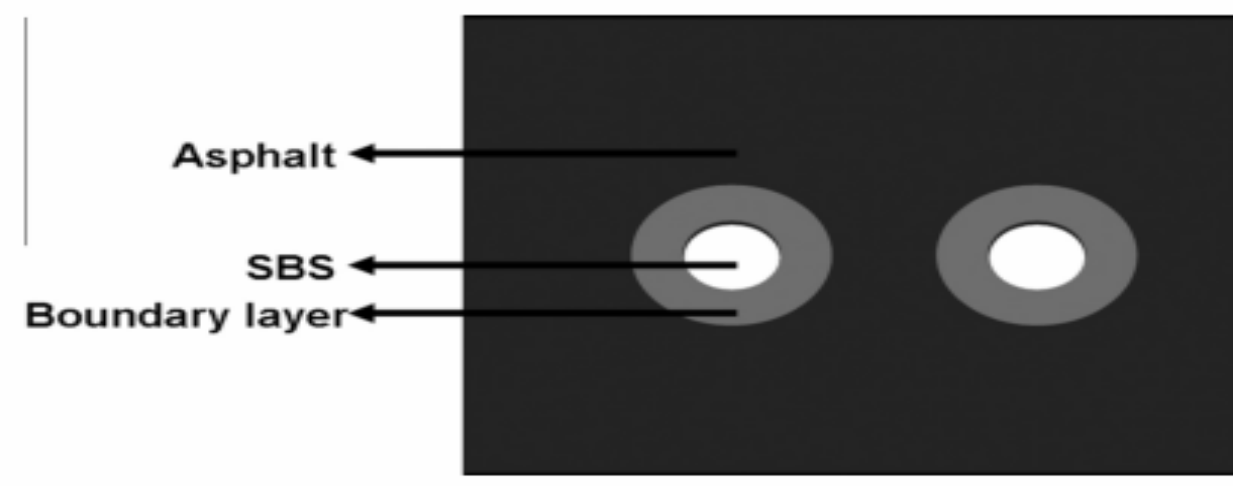

Fig. 3: Modification mechanism of SBS modified asphalt 


\section{Separation of asphalt into four fractions: (SARA)}

This was accomplished according (ASTM D4124, 2009). The principle of the separation method is based on the different SARA fractionation of asphalt into four Fractions using different solvents in a chromatography column using alumina.

\section{Spectralstudy}

In order to identify the general formula, to separate compounds and determine the effective groups, IR spectroscopy was used.

\section{Testing Methodology}

To study the effect of polymer modification on asphalt cement properties, the following conventional tests were conducted on the prepared blends of the modified and original asphalt.

\section{Conventional Measurements}

Softening pointtest (ASTM D 36, 2009), Penetration test (ASTM D 5, 2006) and ductility test (ASTM D 113, 2007).

In addition, the temperature susceptibility of the modified bitumen samples has been calculated in terms of penetration index (PI) using the results obtained from penetration and softening point tests. Temperature susceptibility is defined as the change in the consistency parameter as a function of temperature. A classical approach related to PI calculation has been given in the Shell Bitumen Handbook as shown with the following equation:

$$
\mathrm{PI}=\frac{1952-500 * \log \left(\mathrm{Pen}_{25}\right)-20 * \mathrm{SP}}{50 * \log \left(\mathrm{Pen}_{25}\right)-\mathrm{SP}-120}
$$

where Pen 25 is the penetration at $25^{\circ} \mathrm{C}$ and SP is the softening point temperature of PMB. (Sengoz et al., 2009).

\section{Elastic recovery test}

The elastic recovery of the asphalt cement is evaluated by measuring the recovery ofthe binder thread formed by the elongation of binder specimen when it is cut down by scissors at standard conditions. The elastic recovery test is carried out as (ASTM D6084, 1997)

\section{Storage stability test}

The storage stability of modified asphalts was measured as follows. The samplewas transferred into an aluminum tube $(32 \mathrm{~mm}$ in diameter and $160 \mathrm{~mm}$ in height). The tube was sealed and stored vertically in an oven at $163^{\circ} \mathrm{C}$ for $48 \mathrm{hr}$, then taken out, cooled to room temperature, and cut horizontally into three equal sections. The samples taken from the top and bottom sections were used to evaluate thestorage stability of the SBR modified asphalts bymeasuring their softening points. Ifthe difference of the softening points between the top and the bottom sections was less than $2.5^{\circ} \mathrm{C}$, the sample was considered to have good high-temperature storage stability. If the softening points differed by more than $2.5^{\circ} \mathrm{C}$, the SBS-modified asphalt was considered to be unstable. (Zhang and $\mathrm{Hu}, 2013$ ).

\section{Morphology of Asphalt}

The morphology was measuredusing amicroscope of the type (Optika B-353Pol) with 100 magnification, describing the microstructure interacting between asphalt and polymer,morphology of the polymer modified asphalt (PMA) by determining the state of dispersion of the polymer within the base asphalt as well as to characterize the nature of the continuous and discontinuous phases.

PMA samples for the morphology analysis were prepared using the following preparation method. After the modified sample was prepared, a glass rod was used dip into the sample immediately and one drop of it was put in the center of a glass slide. Then, this drop was covered by a piece of cover glass. In order to obtain smooth surface of the sample for nice observation, the covered sample was heated up to $135^{\circ} \mathrm{C}$ at a certain heating rate in an oven, and a translucent film was formed on the glass slide after about $10 \mathrm{~min}$. After this, the film covered with a cover glass was cooled down to the room temperature (Sengoz et al., 2009). 


\section{Fraction Asphalt}

\section{RESULTS ANALYSIS AND DISCUTION}

Asphalt can be divided into four parts, as shown in the Fig. (4) which shows that the asphalteneratio represents $19 \%$ of the overall asphalt composition. The separated maltenes by a chromatography column, shared that asphalt was found to be rich with aromatic compounds compared to saturated compounds, as described in (Table 2).

\section{Table 2: The contents and appearances of SARA fractions in asphalt}

\begin{tabular}{|c|c|c|}
\hline SARA fraction & Content (wt \%) & Appearance \\
\hline Saturates & $19.53 \%$ & Colourless or Yellow Oil \\
\hline Aromatics & $26.80 \%$ & Yellow or red sticky liquid \\
\hline Resins & $29.47 \%$ & Brown viscous semi-solid \\
\hline Asphaltenes & $19 \%$ & Black fragile powder solid \\
\hline
\end{tabular}

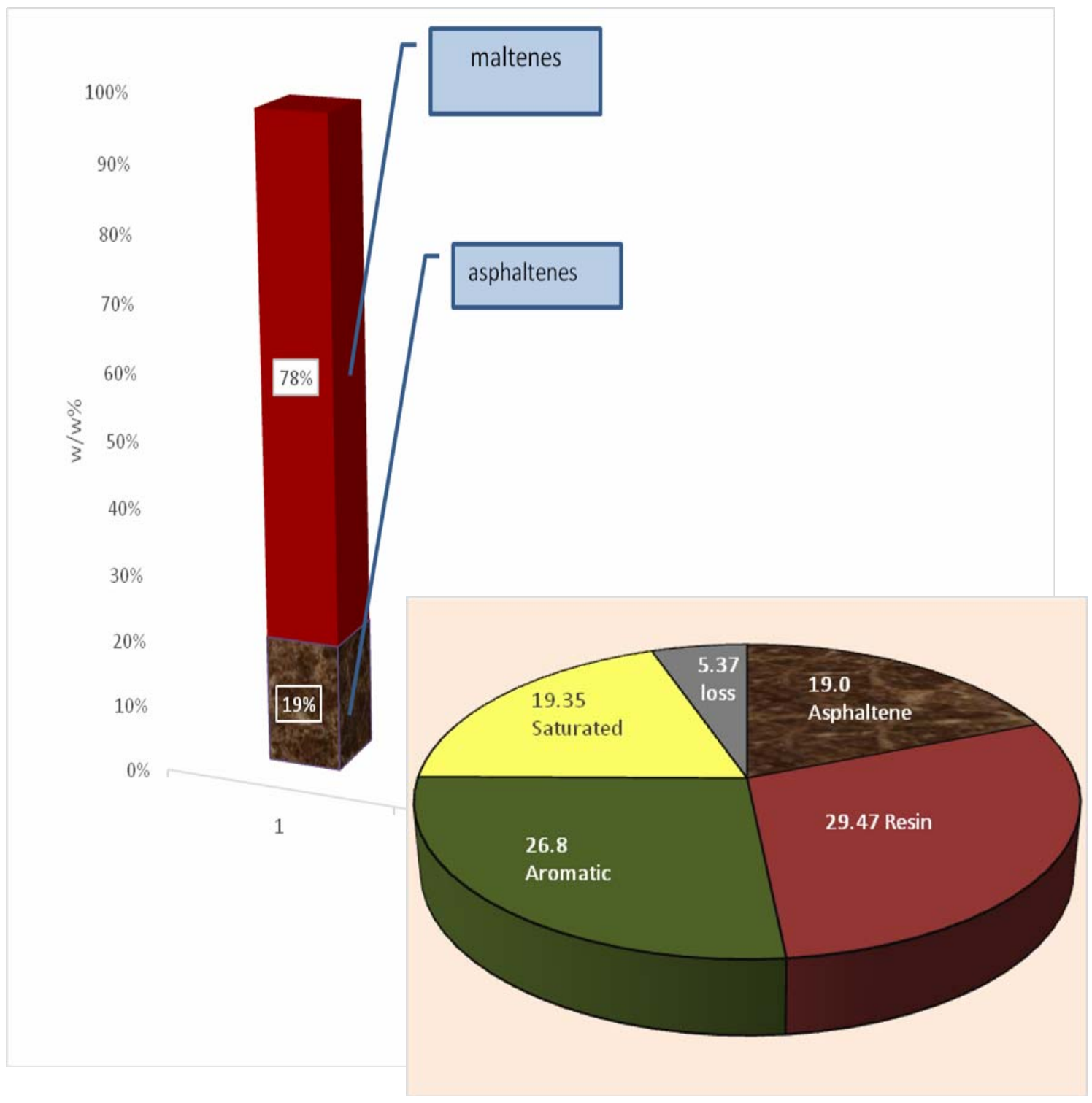

\section{Spectral study}

Fig. 4: Fractions of asphalt 2016)

It has been done by obtainingthe spectral packages in the (Table 3), (Abdul-Jaleel et al., 
Table 3: Spectral packages for fraction asphalt

\begin{tabular}{|c|c|c|c|c|}
\hline Group & Asphaltene & saturated & Aromatic & Resins \\
\hline${\mathrm{O}-\mathrm{H}_{\text {st. }}}$ & $* * * * * *$ & $* * * * *$ & 3448 & 3394 \\
\hline $\mathrm{C}-\mathrm{H}_{\text {st. }}$ & $2923-2854$ & $2924-2854$ & $2920-2851$ & $2924-2854$ \\
\hline $\mathrm{C}=\mathrm{O}_{\text {st }}$ & 1692 & $* * * * *$ & $* * * *$ & 1703 \\
\hline $\mathrm{C}=\mathrm{C}_{\mathrm{ro}}$ & $1610-1550$ & $1655-1562$ & 1564 & 1603 \\
\hline $\mathrm{C}-\mathrm{H}_{\text {be. }}$ & 1459 & 1460 & 1459 & 1460 \\
\hline${\mathrm{C}-\mathrm{H}_{\text {be }}}$ & 1377 & 1377 & 1375 & 1375 \\
\hline${\mathrm{C}-\mathrm{O}_{\text {st }}}^{*}$ & 1185 & $* * * * *$ & $* * * * *$ & 1161 \\
\hline$=\mathrm{C}-\mathrm{H}_{\text {oop }}$ & 1061 & $* * * * *$ & 1016 & 1032 \\
\hline & 968 & $* * * * *$ & $* * * * *$ & $* * * * *$ \\
\hline $\mathrm{C}-\mathrm{X}_{\text {st }}$ & 688 & $* * * * *$ & $* * * * *$ & 739 \\
\hline
\end{tabular}

${ }^{*}$ Carboxylic acids, esters, ether/ $* *$ alcohols, phenols $/ /$ oop $=$ out of plane, $\mathrm{st}=$ stretching, ro=Rock, be $=$ bend

It has been observed that there are wide peaks at $\left(3448,3394 \mathrm{~cm}^{-1}\right)$ related to stretching $\mathrm{OH}$, in alcohols and phenols, peak at $\left(2923-2851 \mathrm{~cm}^{-1}\right)$ to four bands related to stretching $\mathrm{C}-\mathrm{H}$, and there peak within range in $\left(1610-1550 \mathrm{~cm}^{-1}\right)$, related to absorption rocking $(\mathrm{C}=\mathrm{C})$ in aromatic ring. and there a sharp medium peak in $\left(1459 \mathrm{~cm}^{-1}\right)$ and within range $\left(1377 \mathrm{~cm}^{-1}\right)$ due to bending of $\mathrm{C}-\mathrm{H}$ it special $-\mathrm{CH}_{2},-\mathrm{CH}_{3}$ for saturated part, and found peak in $\left(1185 \mathrm{~cm}^{-1}\right),\left(1161 \mathrm{~cm}^{-1}\right)$ related to stretching $\mathrm{C}-\mathrm{O}$ for groups phenols and alcohols. It is worth mentioning thatbands are found in $\left(1016 \mathrm{~cm}^{-1}\right)$. It is related to band out of plane Figs. (5- 8), that shows the spectral study of asphalt parts.

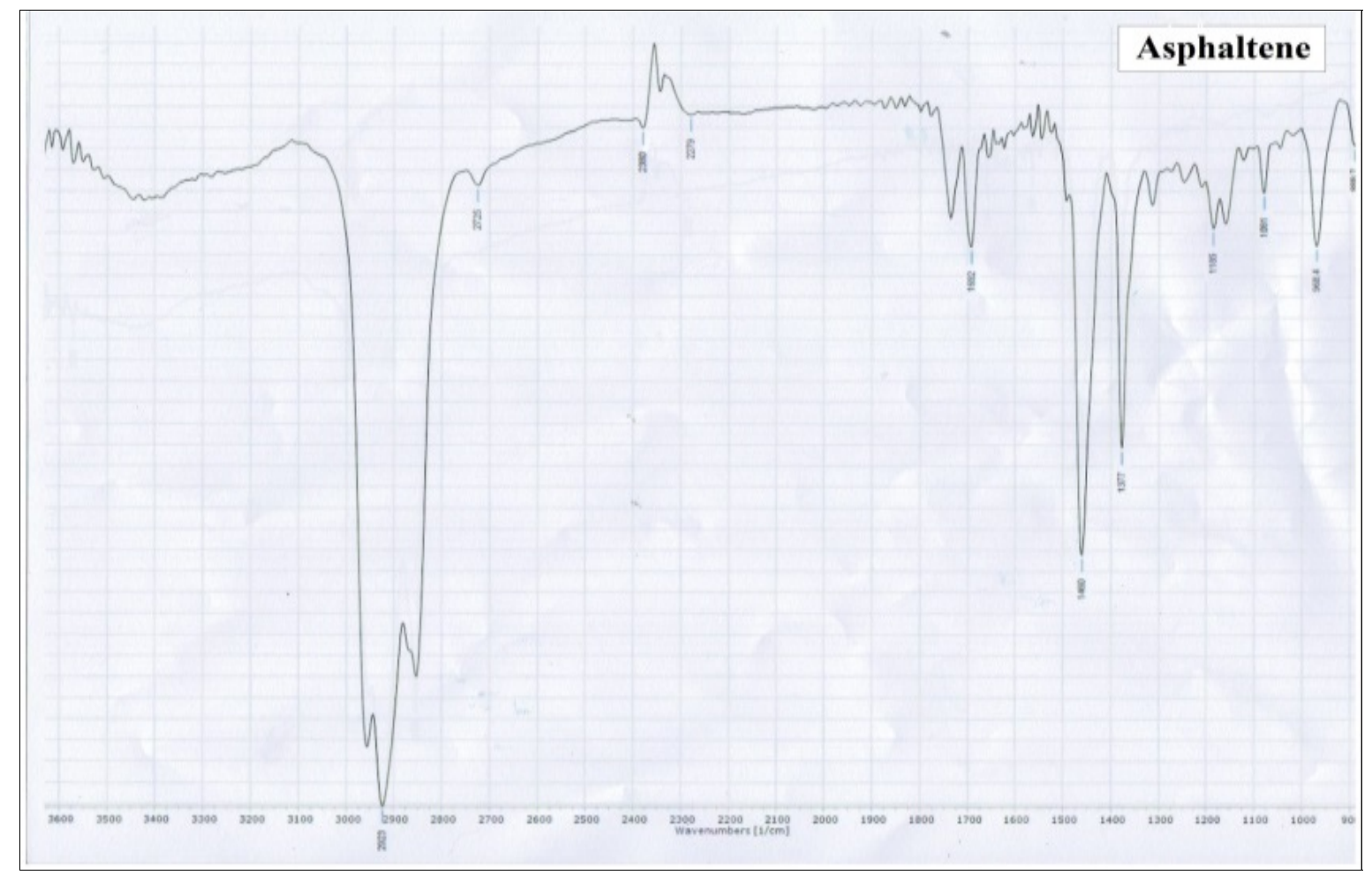

Fig. 5: IR spectrum for asphaltene 


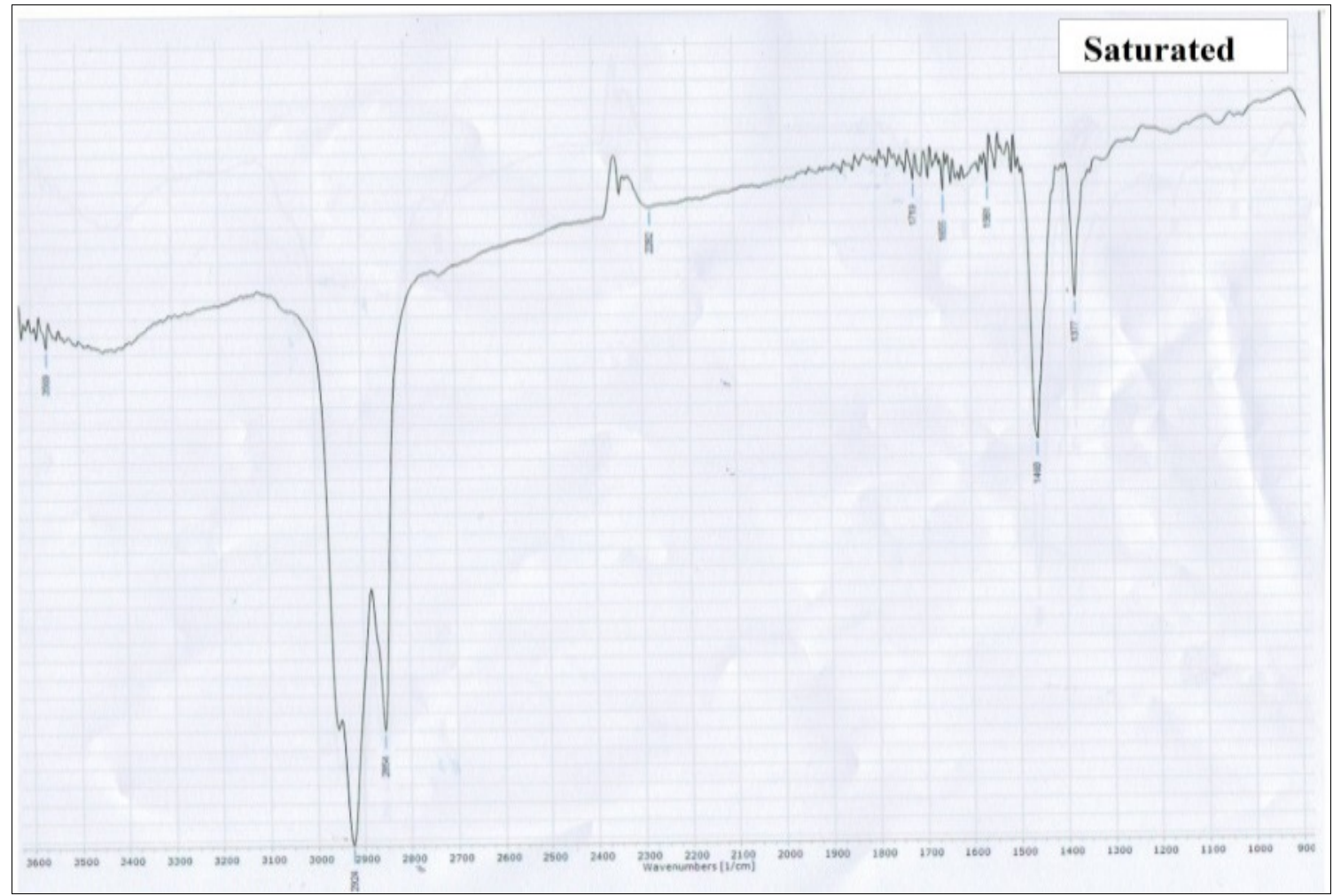

Fig. 6: IR spectrum for saturated

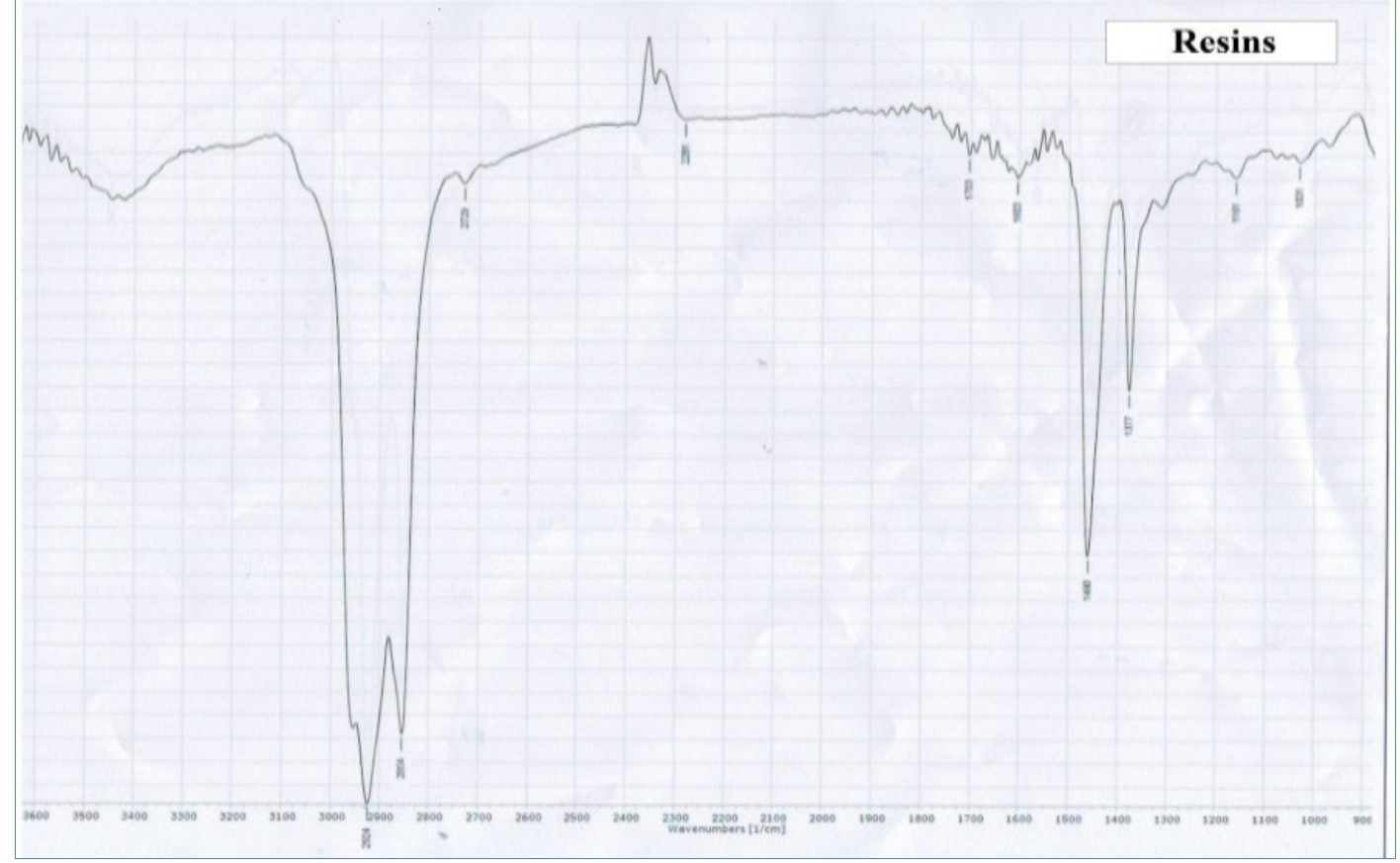

Fig. 7: IR spectrum for resin 


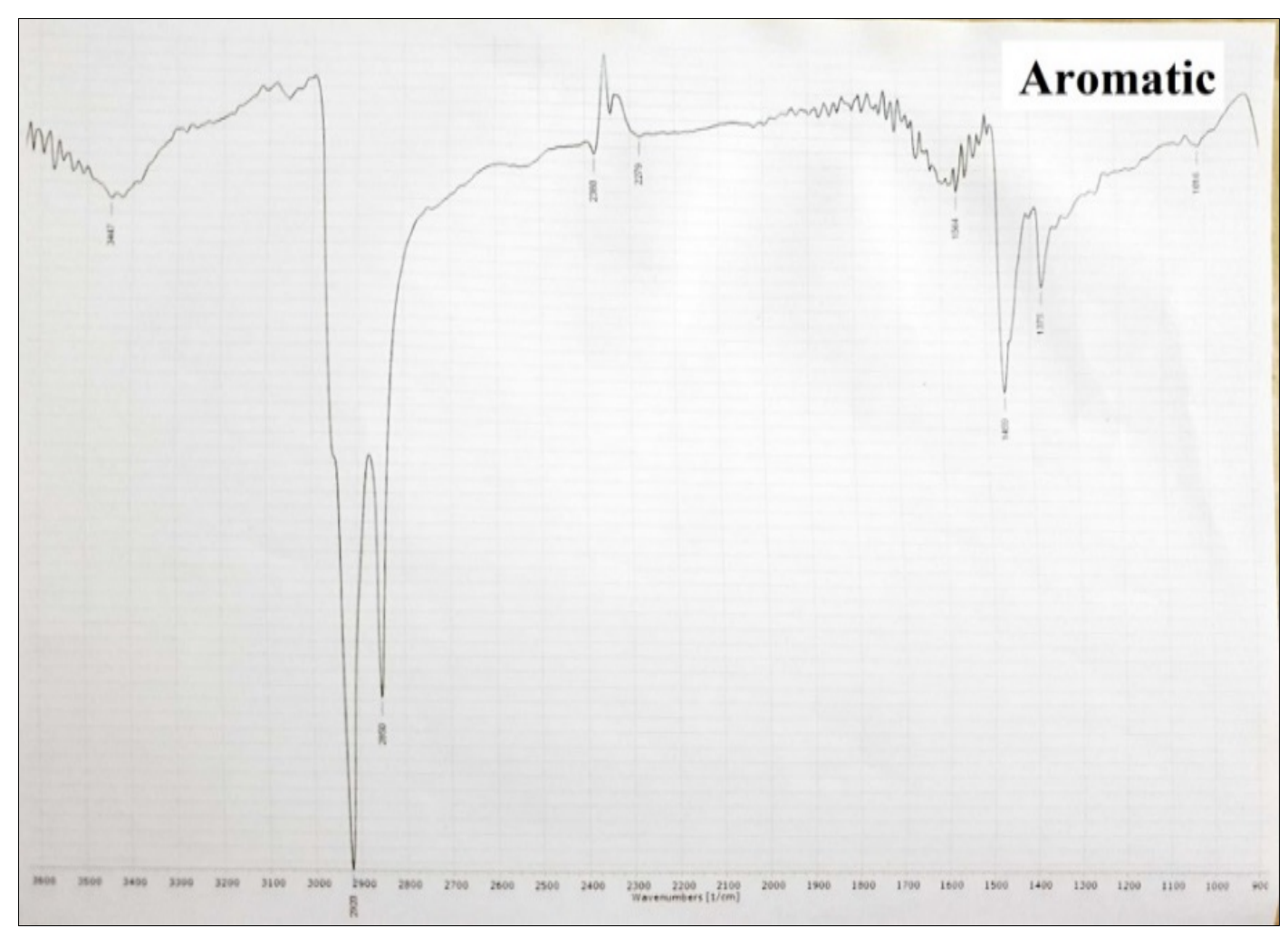

Fig. 8: IR spectrum for aromatic part

\section{Physical measurements}

After the addition ofSBS to asphalt and physical measurements, the results obtained are given in Fig. (9).

As noted in the values listed in the (Table 4), the differences in the softening point between the top and bottom sections of the samples $(2 \%, 3 \%)$ were not more than $2.5^{\circ} \mathrm{C}$. It can bededuced that fresh prepared asphalt binder can be used inpavement at once and can be stored at room temperaturefor long. (Fu and Xie, 2007)

The effect of SBS Polymer modification on the properties of the original asphalt could be seen in Fig. (9) as decrease in penetration values and an increase in softening points with increasing polymer contents. The increase in softening point temperature is favorable since asphalt with higher softening point may be less susceptible to permanent deformation (rutting).

Polymer modification reduces temperature susceptibility of the asphalt; lower values of PI indicate temperature susceptibility. Asphalt mixtures containing asphalt with higher PI are more resistant to low temperature cracking as well as permanent deformation. (Lux,1997).

Table 4: Storage stability of polymer modified asphalt

\begin{tabular}{|c|c|c|c|c|}
\hline \multirow[b]{2}{*}{$\%$ SBS } & \multirow[b]{2}{*}{$\begin{array}{c}\text { Softening Point } \\
\left({ }^{\circ} \mathrm{C}\right)\end{array}$} & \multicolumn{3}{|c|}{ Storage stability } \\
\hline & & $\begin{array}{l}\text { S.P }\left({ }^{\circ} \mathbf{C}\right) \text { at } \\
\text { Bottom }\end{array}$ & S.P $\left({ }^{\circ} \mathrm{C}\right)$ at Top & $\Delta \mathrm{T}$ \\
\hline $0 \%$ & 51.5 & & & \\
\hline $1 \%$ & 56 & 56 & 59 & 3 \\
\hline $2 \%$ & 60 & 50 & 51 & 1 \\
\hline $3 \%$ & 60 & 53 & 51 & 2 \\
\hline $5 \%$ & 74 & 53 & 63 & 10 \\
\hline
\end{tabular}



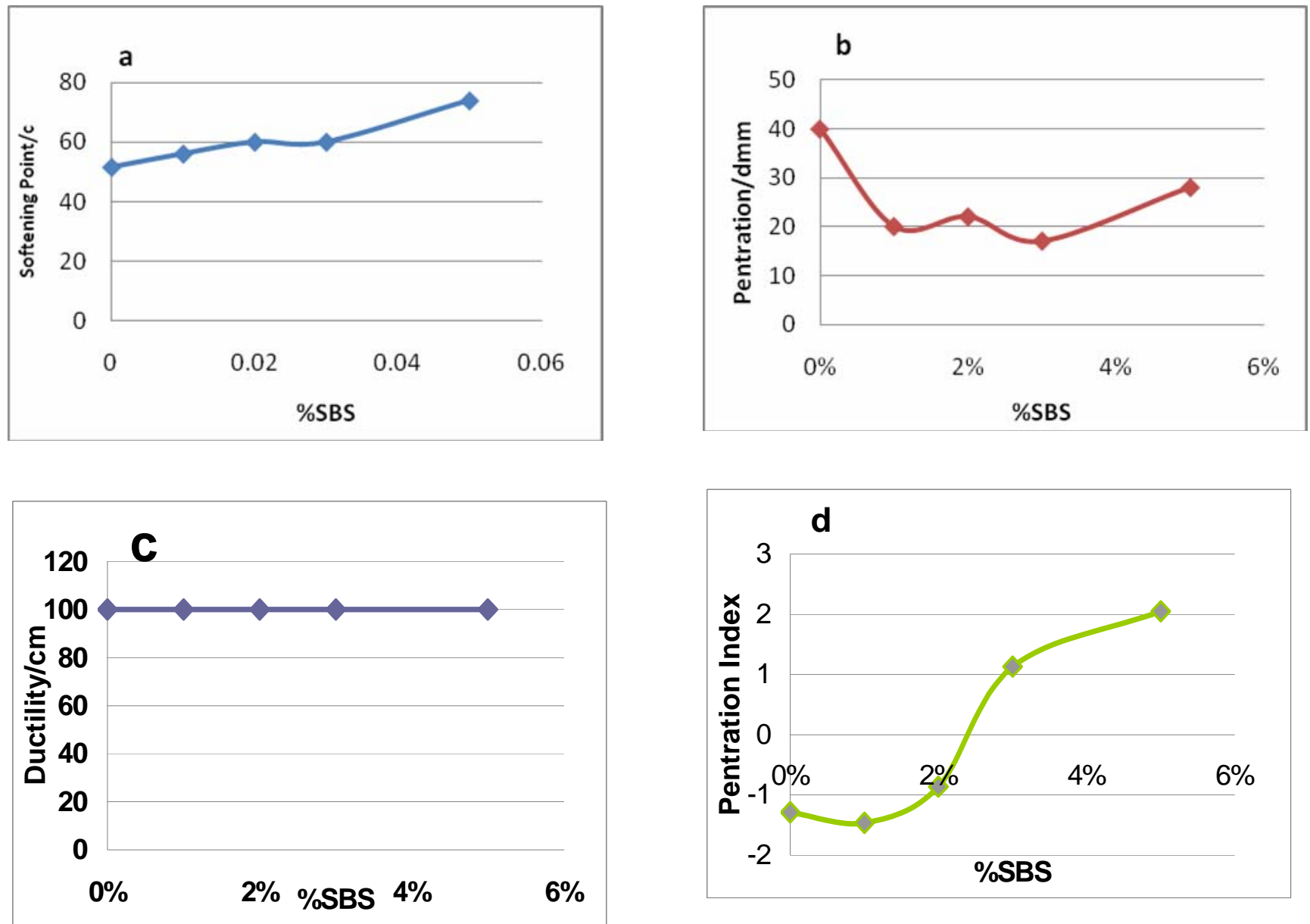

Fig. 9:physical properties after adding the polymer to the asphalt (a: softening point, b: penetration at $25^{\circ} \mathrm{C}$, c: ductility (cm), d: Penetration index)

\section{Image Processing and Analysis}

In this study, the image processing and analysis were used to quantify particle size distribution of SBS in the PMAs.

A distinction could be made between the PMAs whose continuousphase is an asphalt matrix with dispersed polymer particles andsamples whose continuous phase is a polymer matrix with dispersed asphalt globules. In the images, the swollen polymer phaseappears (light) while the asphalt phase appears dark. Where observed in the pictures below Fig. (12), the light phase in the picture represents the swollen polymer, and the dark phase is the asphalt. SBS is dispersed as small particles in the asphalt (Chen et al., 2002). 


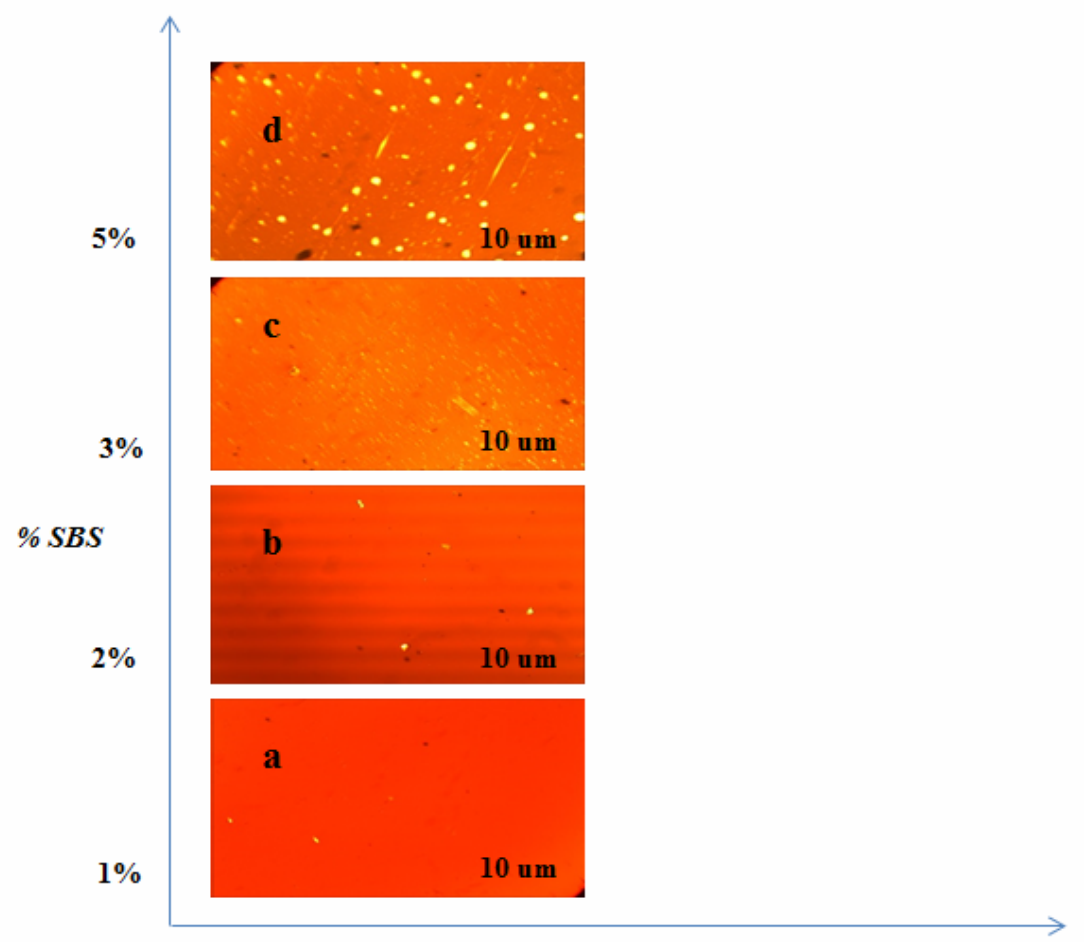

Fig. 12: Image of SBS PMA sample with 400 magnifications

\section{CONCLUSION}

The contents of saturates, aromatic, resins and asphaltenes are $19.5 \%, 26.8 \% 29.4 \%$ and 19\% in asphalt binder, respectively. The contents of aromatics and resins are higher than those of saturates and asphaltenes.

The addition of SBS D1192 led to the creationofa3D network in the asphalt blends and enhanced rheological properties.

\section{REFERENCES}

Abdul-Jaleel, T.; Salem, J.W.; Najres, A.M. (2016). A new separation, fractionation and improving of Abu- Aljeerasphalt. Anbar J. Engineering Sci. AJES, 7(1), 31-41.

Airey, G. (2003). Rheological properties of styrene butadiene styrene polymer modified road Asphalt cements. Fuel, Elsevier Sci. Ltd, 82, 1709-1719.

Alam, S.; Hossain, Z. (2017). Changes in fractional compositions of PPA and SBS modified asphalt binders. Cons. and Bui. Mate., 152, 386-393.

Al-Layla, N.M. (2006). Modification of Rheological Properties of Asphalt by Treatment with Reclalaime Rubber from Scrap Tires $\backslash$ Effect Modification Treatment on the Properties of the Modified Asphalt. Raf. J. Sci., 17, 39-46.

ASTM D 113, (2007). "Standard Test Method for Ductility of Bituminous Materials". Annual Book of ASTM Standards, V 4.03.

ASTM D 36, (2009). "Standard Test Method for Softening Point of Bitumen (Ring-and Ball Apparatus)". Annual Book of ASTM Standards, V 4.04.

ASTM D 5, (2006). "Standard Test Method for Penetration of Bituminous Materials". Annual Book of ASTM Standards, V 4.03.

ASTM D4124, (2009). "Standard Test Method for Separation of Asphalt in to Four Fraction". Annual Book of ASTM Standards, V 4.04.

ASTM D6084, (1997). 'Standard Test Method for Elastic Recovery of Bituminous Material". Annual Book of ASTM Standards, V 4.02.

Chen, J.S.; Liao, M.C.; Shiah, M.S. (2002). Asphalt Modified by SBS triblock copolymer: morphology and model. Mat. in C. Eng., 14(3), 224-229. 
Firoozifar, S.H.; Foroutan, S. (2014). The effect of asphaltene on thermal properties of bitumen. Chem. Eng. Res. Des., 89, 2044-2048..

Fu, H.; Xie, L. (2007). Storage stability and compatibility of asphalt binder modified by SBS graft copolymer. Construction and Building Materials. 21, 1528-1533.

Kareem, Y.N.A. (2016). Effect of polymer modification on asphalt cement properties. Diyala J. Eng. Sci., 09(03), 1-11.

Lux, I.U. (1997). Choracterization of SBS Polymer modified bitumen comparison of conventional methods and DMA. J. Test Eval., 383-90.

Navarro, F.J.; Partal, P. (2009). Bitumen medication with reactive and non-reactive (virgin and recycled) polymers: A comparative analysis. J. Industrial and Engineering Chem., 15, $458-464$.

Polacco, G.; Filippi, S.; Merusi, F. (2015). A review of the fundamentals of polymer-modified asphalts: Asphalt/ polymerinteractions and principles of compatibility. Advances in Colloid and Interface Sci., 224,72-112.

Salih, L.A. (2008). Effect of air blowing of qaiyarah asphalt on the stability of (Asphalt-Sulfur) blends. Raf. J. Sci., 19, 174-190.

Salomon, D.R. (2006). "Asphalt Emulsion Technology". Transportation Research Board Characteristics of Bituminous Materials Committee. Washington, DC, USA, E-C102,5-7.

Sengoz, B.; Topal, A.; Isikyakar, G. (2009). Morphology and image analysis of polymer modified bitumens. Cons. and B. Mat., 23, 1986-1992.

Swamy, A.K.; Rongali, U.D.; Jain, P.K. (2017). Effect of HDPEH polymer on viscoelastic properties of SBS modified asphalt. Construction and Building Materials, 136, 230-236.

Zhang, F.; Hu, C. (2013). The research for SBS and SBR compound modified asphalts with polyphosphoric acid and sulfur. Construction and Building Materials. 43, 461-468

Zhang, F.; Yu, J.; Wu, S. (2010). Effect of ageing on rheological properties of storage-stable SBS/sulfur-modified asphalts. J. Hazardous Materials, 182, 507-517. 